\title{
Antibacterial Activity of Nanocomposites of Copper and Cellulose
}

\author{
Ricardo J. B. Pinto, ${ }^{1}$ Sara Daina, ${ }^{2}$ Patrizia Sadocco, ${ }^{2}$ \\ Carlos Pascoal Neto, ${ }^{1}$ and Tito Trindade ${ }^{1}$ \\ ${ }^{1}$ Department of Chemistry; CICECO, University of Aveiro, 3810-193 Aveiro, Portugal \\ ${ }^{2}$ Innovhub-SSI Divisione Carta, Via Giuseppe Colombo, 83-20133 Milan, Italy \\ Correspondence should be addressed to Ricardo J. B. Pinto; r.pinto@ua.pt
}

Received 30 April 2013; Revised 26 September 2013; Accepted 1 October 2013

Academic Editor: Hélder A. Santos

Copyright (C) 2013 Ricardo J. B. Pinto et al. This is an open access article distributed under the Creative Commons Attribution License, which permits unrestricted use, distribution, and reproduction in any medium, provided the original work is properly cited.

\begin{abstract}
The design of cheap and safe antibacterial materials for widespread use has been a challenge in materials science. The use of copper nanostructures combined with abundant biopolymers such as cellulose offers a potential approach to achieve such materials though this has been less investigated as compared to other composites. Here, nanocomposites comprising copper nanofillers in cellulose matrices have been prepared by in situ and ex situ methods. Two cellulose matrices (vegetable and bacterial) were investigated together with morphological distinct copper particulates (nanoparticles and nanowires). A study on the antibacterial activity of these nanocomposites was carried out for Staphylococcus aureus and Klebsiella pneumoniae, as pathogen microorganisms. The results showed that the chemical nature and morphology of the nanofillers have great effect on the antibacterial activity, with an increase in the antibacterial activity with increasing copper content in the composites. The cellulosic matrices also show an effect on the antibacterial efficiency of the nanocomposites, with vegetal cellulose fibers acting as the most effective substrate. Regarding the results obtained, we anticipate the development of new approaches to prepare cellulose/copper based nanocomposites thereby producing a wide range of interesting antibacterial materials with potential use in diverse applications such as packaging or paper coatings.
\end{abstract}

\section{Introduction}

The overuse of conventional antibiotics has led to new strains of bacteria with increasing levels of resistance posing potential problems for the public health. There have been efforts from diverse scientific fields in order to achieve solutions that might contribute to attenuate this problem. In this context, research on new bactericidal materials has become a current and important goal in materials science [1]. The development of polymer based nanocomposites with antimicrobial activity offers interesting possibilities because the polymer matrix can be varied in order to fulfill not only specific technological requirements but also nanostructures with size- and shapedependent properties that can be exploited [2].

Various inorganic nanostructures have been used in a wide range of matrices that result into materials with antibacterial properties $[3,4]$. Among the polymer nanocomposites investigated so far, those incorporating $\mathrm{Ag}$ and $\mathrm{Cu}$ nanoparticles have been regarded as particularly useful for applications in various fields, including biomedical equipment and devices, water treatment, and food processing $[3,5]$. Silver has been widely investigated regarding its antimicrobial activity due to its superior effectiveness and strong cytotoxicity towards a broad range of microorganisms, such as bacteria and fungi [1]. The efficacy of Ag NPs as antimicrobial agent is well established and silver based materials have been used in a variety of commercial products. Although there is strong evidence that the antimicrobial activity of silver is associated with cationic release, the mechanism is not totally understood posing some concerns about the potential cytotoxicity and genotoxicity in human cells $[6,7]$. In this context, it seems of interest to search for alternatives that could replace, if not totally, at least to some extent silver nanoparticles used as fillers in some composite materials. Copper is of natural 
occurrence in plant and animal tissues where it participates in a number of important roles. To certain limits, the human body has mechanisms available for protection against copper toxicity at the cellular, tissue, and organ levels [8, 9]. It has been reported that $\mathrm{Cu}$ NPs have bactericidal effects comparable to Ag nanoparticles in single strains of $E$. coli and $B$. subtilis [10].

The great interest for $\mathrm{Cu}$ based composites can be easily perceived by the number of polymer matrices investigated in their preparation, both of synthetic and natural origin [11]. Among the biopolymers used, the polysaccharides, cellulose $[8,12]$, starch [13], and chitosan [14], have received special attention. These are renewable polymers with potential biocompatibility and biodegradability that can be used in a variety of formulations depending on the envisaged functionality [15].

Following our own interest in developing silver based antimicrobial materials $[16,17]$, we report here our first study on the antibacterial activity of bionanocomposites made of copper and bacterial (BC) and vegetable cellulose (VC). This research follows our recent findings that the chemistry of $\mathrm{Cu}$ nanostructures, in ambient conditions and when incorporated in cellulose matrices, depends on the morphological features of the copper particles as well as on the type of cellulose employed [12]. Although bacterial and vegetable cellulose are identical from a chemical point of view, their distinct microstructures seem to influence the chemical stability of incorporated copper nanostructures, thereby with potential effects on the antibacterial properties of the corresponding composites. Hence, this research will have focus on the antibacterial activity of nanocomposites in which the cellulose matrices are different and at the same time matching $\mathrm{Cu}$ nanofillers with distinct morphologies (spherical NPs and NWs).

\section{Materials and Methods}

2.1. Materials. All chemicals were used as received: copper (II) sulphate pentahydrate (p.a., Panreac), copper (II) nitrate trihydrate (p.a., RPE), trisodium citrate (99\%, BDH), sodium borohydride $\left(\mathrm{NaBH}_{4}\right)$ (95\%, Riedel-de Haën), sodium hydroxide (98,5\%, Acrôs Organics), ethylenediamine (99\%, Aldrich), and hydrazine hydrate (50-60\%, Sigma-Aldrich). Wood cellulose fibers (Eucalyptus globulus, ECF bleached kraft pulp, average length $0.9 \mathrm{~mm}$, average width $20 \mu \mathrm{m}$ ) composed essentially of cellulose $(\sim 85 \%)$ and glucuronoxylan ( $15 \%)$ were supplied by Portucel (Portugal). Wood cellulose was disintegrated and washed with distilled water before use. Pure bacterial cellulose was produced by Acetobacter xylinum, in the form of a wet 3D network of ribbon-like nanofibril structures (50-100 $\mathrm{nm}$ width).

\subsection{Preparation of the Cellulose/Copper NPs Nanocomposites.} The preparation of the nanocomposites containing $\mathrm{Cu}$ NPs was performed by an adaptation of the procedure described by Loo et al. [18] for $\mathrm{Cu}$ hydrosols but by reducing the copper (II) salt in the presence of vegetable or bacterial cellulose fibers. Thus, the fibers were homogeneously mixed with $5 \mathrm{~mL}$ of $\mathrm{CuSO}_{4} \cdot 5 \mathrm{H}_{2} \mathrm{O}\left(1 \times 10^{-2} \mathrm{M}\right)$ and $60 \mathrm{~mL}$ of a sodium citrate solution $\left(5 \times 10^{-3} \mathrm{M}\right)$, over 1 hour. This suspension was purged under a $\mathrm{N}_{2}$ stream and then $30 \mathrm{~mL}$ of $\mathrm{NaBH}_{4}(2 \times$ $\left.10^{-2} \mathrm{M}\right)$ and $30 \mathrm{~mL}$ of $\mathrm{NaOH}\left(2 \times 10^{-2} \mathrm{M}\right)$ were added drop wise, under vigorous stirring. The mixture was then stirred and maintained under $\mathrm{N}_{2}$ atmosphere for 1 hour. The nanocomposites acquired a red color after complete copper (II) reduction, after which the product was collected by filtering and thoroughly washed with distilled water. The VC nanocomposites were dried overnight in a desiccator with silica gel and the BC nanocomposites were lyophilized.

\subsection{Preparation of the Cellulose/Copper NWs Nanocomposites.}

The copper NWs were prepared by reduction of copper (II) nitrate with hydrazine in alkaline medium [19]. An aqueous solution $(1 \mathrm{~mL})$ of $\mathrm{Cu}\left(\mathrm{NO}_{3}\right)_{2} \cdot 3 \mathrm{H}_{2} \mathrm{O}(0.1 \mathrm{M})$ was mixed with $20 \mathrm{~mL}$ of $\mathrm{NaOH}(15 \mathrm{M})$ aqueous solution. This solution was kept under $\mathrm{N}_{2}$ and then $150 \mu \mathrm{L}$ of ethylenediamine and $25 \mu \mathrm{L}$ of hydrazine were added, by this order, to the reacting mixture. The temperature of this mixture was set to $60^{\circ} \mathrm{C}$, with vigorous stirring, for a period of 1 hour.

The cellulose nanocomposites containing the nanowires were prepared by mixing $\mathrm{Cu}$ NWs and cellulose (VC or BC) fibers in $20 \mathrm{~mL}$ of water. This mixture was kept under constant stirring, at room temperature, over $3 \mathrm{~h}$. The resulting nanocomposites were collected by filtering and thoroughly washed with distilled water. The VC nanocomposites were dried and the BC nanocomposites were lyophilized.

2.4. Stock Cultures and Culture Media. All microbial strains cited in the paper were provided by DSMZ, Deutsche Sammlung von Mikroorganismen und Zellkulturen GmbH (German Collection of Microorganisms and Cell Cultures). $K$. pneumoniae ATCC 4352 (DSM 789) and S. aureus ATCC 6538 (DSM799) were maintained frozen $\left(-80^{\circ} \mathrm{C}\right)$ and transferred monthly on TSA (Tryptone Soya Agar) made of $15 \mathrm{~g} / \mathrm{L}$ tryptone, $5 \mathrm{~g} / \mathrm{L}$ soya peptone, $5 \mathrm{~g} / \mathrm{L} \mathrm{NaCl}$, and $15 \mathrm{~g} / \mathrm{L}$ neutralized bacteriological agar.

2.5. Quantitative Assessment of Antibacterial Activity of Cellulose/Cu Nanocomposites. All bacterial preinoculum cultures were grown overnight at $37^{\circ} \mathrm{C}$ in $20 \mathrm{~mL}$ of Nutrient Broth (made of $1 \mathrm{~g} / \mathrm{L}$ beef extract; $5 \mathrm{~g} / \mathrm{L}$ neutralized peptone; $2 \mathrm{~g} / \mathrm{L}$ yeast extract; $5 \mathrm{~g} / \mathrm{L} \mathrm{NaCl}$ ) subjected to horizontal shaking at $100 \mathrm{rpm}$. The nanocomposite samples were placed in contact with a microbial liquid suspension, subjected to vigorous shaking in order to assure the best contact between bacteria and sample. At $0 \mathrm{~h}$ and $24 \mathrm{~h}$ contact times, the bacterial concentration $(\mathrm{CFU} / \mathrm{mL})$ of the microbial suspension was determined by plating serial dilution on Plate Count Agar to obtain the overall number of bacteria (CFU-Colony Forming Units). For the antibacterial tests the specific conditions were as follows:

(i) microbial liquid suspension: $5 \mathrm{~mL}$ of $5 \%$ Nutrient Broth in phosphate buffer $(0.3 \mathrm{mM}, \mathrm{pH} 7.2)$ inoculated with $10^{-4}-10^{-5} \mathrm{CFU} / \mathrm{mL}$ bacteria;

(ii) total flask volume: $25 \mathrm{~mL}$;

(iii) sample incubation: 24 hours at $23 \pm 1^{\circ} \mathrm{C}$ under vigorous shaking; 
(iv) quantity of tested material: $100 \mathrm{mg}$ for vegetable cellulose based samples and $50 \mathrm{mg}$ for bacterial cellulose based samples. The samples were cut in small pieces and tested in duplicate;

(v) control samples: BC and CV fibers without the addition of $\mathrm{Cu}$ were tested as blank reference, while as internal reference of the method the bacteria growth was tested on flasks only containing inoculated Broth media. All the samples were subjected to sterilization by autoclave.

The bacteria log reduction of the samples was calculated as follows: $\log$ reduction $=\log \left(\mathrm{CFU} \mathrm{T}_{24}\right.$ control sample $)-$ $\log \left(\mathrm{CFU} \mathrm{T} \mathrm{T}_{24}\right.$ nanocomposite). As mentioned in the standard dynamic shake flask method, at least a 1 log reduction of bacteria load is required to claim antibacterial property.

2.6. Instrumentation. Scanning electron microscopy (SEM) images were obtained using a Hitachi SU-70 instrument fitted with an energy dispersive spectroscopy (EDX) accessory (EDX Detector: Brüker AXS, Software: Quantax). Samples were deposited on a glass plate and coated with carbon.

The diameter of the $\mathrm{Cu}$ nanoparticles was determined by analysis of SEM micrographs of the BC/Cu NPs nanocomposites. In this case, at least $50 \mathrm{NPs}$ were analyzed using ImageJ program and the average value and its standard deviation were calculated, respectively.

The optical spectra were recorded using a Jasco V-560 UV-Vis spectrophotometer; for solid samples the spectra were recorded in the diffuse reflectance mode using $\mathrm{MgO}$ as the reference. Inductively Coupled Plasma Optical Emission Spectrometry (ICP-OES), using a Jobin Yvon 70 Plus equipment, was used to determine the copper content. Typically, the samples are digested in a microwave at $160^{\circ} \mathrm{C}$ with concentrated nitric acid before analysis.

\section{Results and Discussion}

A number of $\mathrm{Cu} /$ cellulose nanocomposites have been prepared using both VC and BC fibers as the matrices. Typically the nanocomposites with Cu NPs were obtained by the in situ reduction of $\mathrm{Cu}(\mathrm{II})$ and $\mathrm{Cu}$ NWs composites analogues were obtained by blending the previously prepared nanowires with the cellulose matrices. Vegetable cellulose was not effective in the formation of ex situ nanocomposites. The BC matrix formed an intimate mixture with the $\mathrm{Cu}$ NWs because the nanofibrils had the ability to be detached from the matrix by rolling up the $\mathrm{Cu}$ NWs. SEM images (Figure 1) show the morphological characteristics of the distinct cellulose/Cu nanocomposites investigated in this research. The $\mathrm{BC} / \mathrm{Cu}$ NPs nanocomposites (Figure 1(a)) present a homogeneous distribution of well-defined spherical Cu NPs (ca. $36 \mathrm{~nm}$ diameter) clustered at the nanofibers surfaces. For the VC nanocomposites (Figure 1(b)), the images show a film over the cellulose fibers probably consequence of the oxidation of the NPs on the surface of this biopolymer. The BC/Cu NWs nanocomposites (Figure 1(a)) show Cu NWs with diameters in the 90-220 $\mathrm{nm}$ range and micrometric lengths blended with BC nanofibrils.

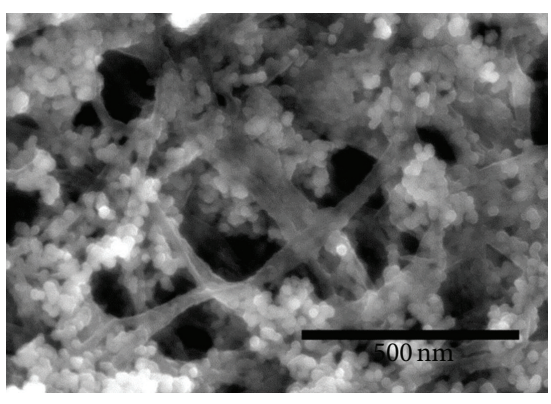

(a)

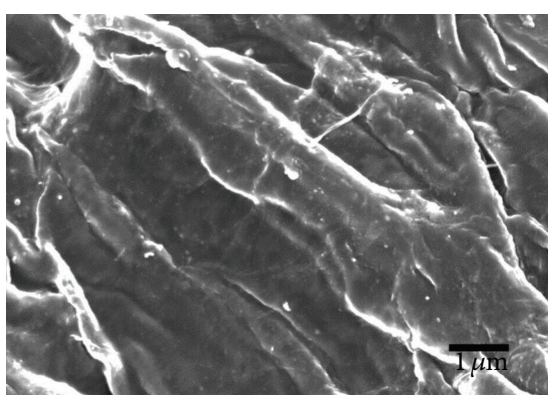

(b)

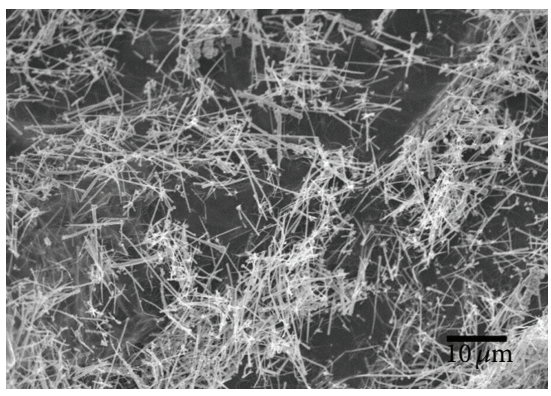

(c)

Figure 1: SEM images of (a) BC/Cu NPs, (b) VC/Cu NPs, and (c) $\mathrm{BC} / \mathrm{Cu} \mathrm{NWs}$ nanocomposites.

Figure 2 shows the optical spectra of the cellulose/copper nanocomposites. Figure 2 shows that the nanocomposite prepared with BC fibers maintained the characteristic surface plasmon resonance (SPR) band in the visible region $(568 \mathrm{~nm})$ assigned to $\mathrm{Cu}$ nanoparticles [20], though a slight redshift was observed as compared to the $\mathrm{Cu}$ aqueous colloid. As discussed in our previous work [12], this shift can be explained by changes in the dielectric function of the surrounding medium (from water to cellulose). The $\mathrm{CV} / \mathrm{Cu}$ nanocomposite does not exhibit the SPR band which has been explained on the basis of the $\mathrm{Cu}$ nanostructures oxidation when exposed to air, thus confirming the results observed in Figure 1(b). These differences are in line with the color observed for all cellulose/copper nanocomposites; thus the BC nanocomposites maintained the characteristic reddish hue of metallic copper while the VC composites acquired a greenish color shortly after their synthesis, due to oxidized copper species [12].

The results above have been explained as consequence of a less chemical stability of Cu NPs grown on VC fibers against 
TABLE 1: Selected cellulose/copper nanocomposites used in the antimicrobial essays.

\begin{tabular}{lcc}
\hline Cellulose substrate & Code & $\mathrm{Cu}(\% \mathrm{w} / \mathrm{w})$ \\
\hline \multirow{2}{*}{ Vegetable cellulose (VC) } & VC & - \\
& VC/NPs & 0.55 \\
\hline & BC & - \\
Bacterial cellulose (BC) & BC/NPs1 & 0.93 \\
& BC/NPs2 & 4.95 \\
& BC/NWs & 5.17 \\
\hline
\end{tabular}

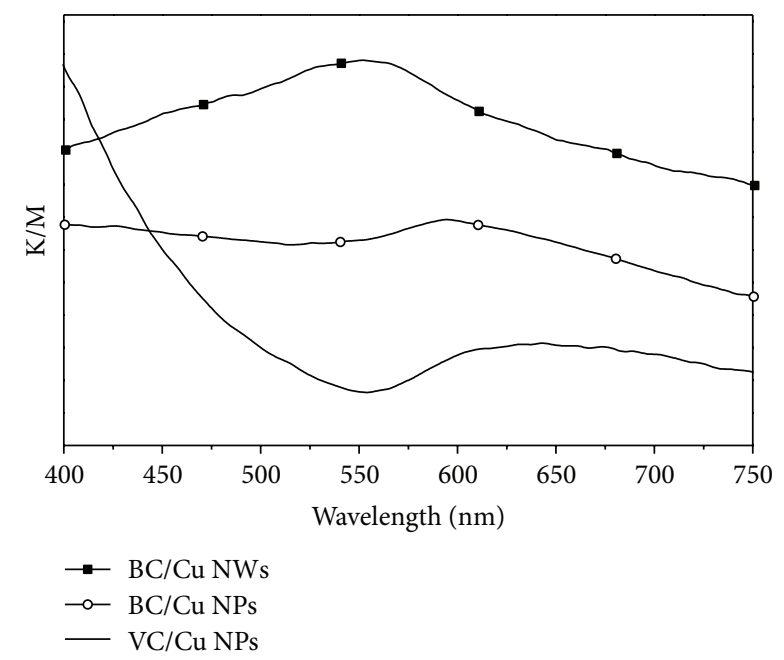

FIGURE 2: Optical spectra of as-prepared cellulose/Cu nanocomposites (Kubelka-Munk data).

oxidation as compared to those present in BC fibers [12]. In fact, although having an identical molecular structure, the VC fibers form a more open structure in which permeation to oxygen is higher than in the case of BC, thus facilitating the oxidation of $\mathrm{Cu}$ NPs attached to the fibers surfaces [12].

In order to evaluate the antibacterial activity of the cellulose/Cu nanocomposites, selected samples have been tested towards bacteria strains of Staphylococcus aureus and Klebsiella pneumoniae. Table 1 lists the selected nanocomposites together with the respective $\mathrm{Cu}$ content as determined by elemental analysis using ICP.

Figure 3 shows the results obtained for the antibacterial activity of the distinct nanocomposites and for blank cellulose matrices used as control. For both bacteria strains the control samples did not exhibit antibacterial activity (value of log CFU at $\mathrm{T}_{24}$ for control samples and the buffer solution was almost identical).

Conversely, the antimicrobial tests revealed that the $\mathrm{Cu}$ nanocomposites have antibacterial action for both bacteria, though with a more pronounced effect in respect to K. pneumoniae. Although there is some debate in the literature about the relative effect of nanoparticles on the type of bacteria, this study is in line with reports that suggest that Gramnegative bacteria are more affected by copper based materials [3]. In Gram-negative bacteria, peptidoglycan layer is thinner (between 2 and $3 \mathrm{~nm}$ ) than Gram-positives (around $30 \mathrm{~nm}$ )

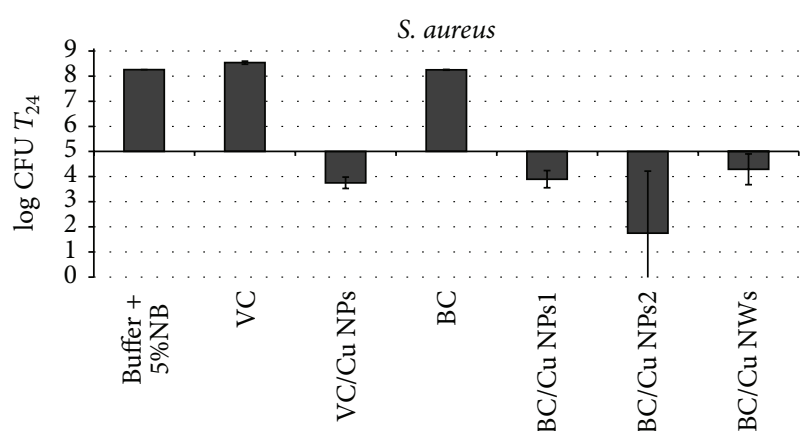

(a)

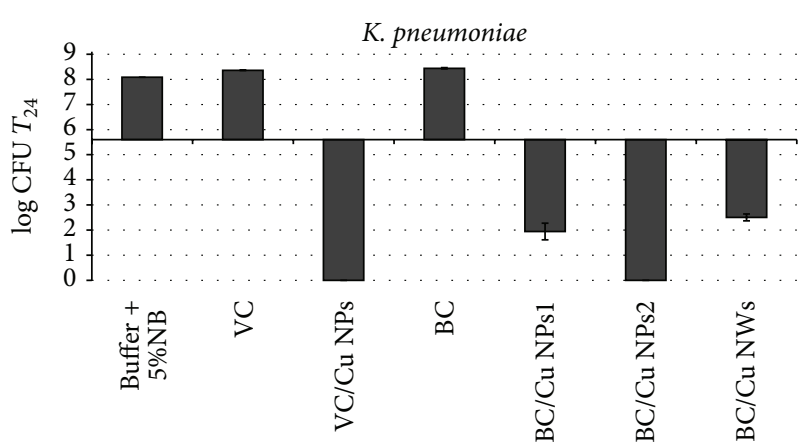

(b)

FIGURE 3: Antibacterial activity of cellulose/ $\mathrm{Cu}$ nanocomposites with variable $\mathrm{Cu}$ content against (a) S. aureus and (b) K. pneumoniae. The log CFU values were determined in the testing Broth after $24 \mathrm{~h}$ contact time and were compared to those of pure cellulose matrices as well as to the inoculated Broth alone. Horizontal dark line refers to the initial inoculum (log CFU at time 0$)$.

and externally to this layer there is an outer asymmetric membrane composed of proteins, phospholipids, and lipopolysaccharides [1]. Some authors have explained the higher antibacterial effect in Gram-negatives bacteria as consequence of interactions occurring between the bacteria outer membrane and solid surfaces, either for nanoparticles of copper $[3,21]$ or of silver [3,22].

Such particle-microorganism interaction promotes the formation of irregular pores in the outer membrane of Gramnegative bacteria, due to direct interaction of the nanoparticles or metallic ions released, changing its permeability and causing the release of cell components. These structural changes result in the membrane degradation and eventually in the death of the bacteria $[22,23]$.

Several studies have reported that the extent of inhibition of bacterial growth in this type of materials depends on the inorganic content in the medium, both for the case of metal NPs and for metal oxides used as fillers [16, 24]. For the nanocomposites investigated here two samples spherical $\mathrm{Cu}$ NPs (BC/Cu NPs1 and BC/Cu NPs2) have been evaluated by varying the $\mathrm{Cu}$ content. The increasing of $\mathrm{Cu}$ content from 0.93 to $4.95 \%(\mathrm{w} / \mathrm{w})$ resulted in a significant bactericidal effect (about 2 log bacterial growth over $24 \mathrm{~h}$ incubation time) against the $S$. aureus. A similar trend was also observed for the $K$. pneumoniae strain, verifying a direct dependence 
of the antibacterial action with the of $\mathrm{Cu}$ content in the composite. Note that complete killing effect was observed for the BC/Cu NPs2 nanocomposite. Similarly to silver materials, the antibacterial activity of $\mathrm{Cu}$ nanostructures has been associated with the release of ionic species and the formation of reactive oxygen species $[1,5]$. The increase of the copper amount in the nanocomposites results in a higher release of cations, increasing in this way the antibacterial activity of the corresponding cellulose based nanocomposites.

It is interesting to note that despite the influence of copper content, the sample with the higher copper content (BC/Cu NWs sample) did not present the higher antibacterial effect. For both bacteria studied, BC/Cu NWs nanocomposite present an antibacterial activity significantly lower (more than $2 \log$ bacterial growth) in relation to the nanocomposite with copper NPs with similar copper amount (BC/Cu NPs2). Even $\mathrm{BC} / \mathrm{Cu}$ NPs1 nanocomposite presents slightly higher antibacterial efficiency, this composite presenting 5 times less copper amount. Assuming that the antibacterial effect is mainly due to cationic release, this lower efficiency for the $\mathrm{Cu}$ NWs containing composites, as compared to those incorporating $\mathrm{Cu}$ NPs, is probably due to the less surface reactivity of the nanowires, thus leading to lower amounts of soluble and oxidized copper species. In fact, this explanation is in agreement with the observations presented above for the easier oxidation of the Cu NPs as compared to that of the $\mathrm{Cu}$ NWs. In fact, the former materials have already oxidized copper phases and the surface chemistry is thus markedly distinct from the Cu NWs.

There is lack of knowledge about the effect of the morphology of copper nanostructures on their antibacterial properties, both in the case of individualized nanoparticles and when used in composite materials. However, studies performed on silver nanostructures with distinct morphologies have demonstrated that Ag NPs undergo a shape-dependent interaction with the bacteria [25]. Through the study of bacteria surface by transmission electron microscopy, the authors found that spherical NPs exhibit enhanced antibacterial activity than, for example, Ag nanorods. This effect was explained by the higher reactivity of these nanostructures because of higher atomic density. In this case, to obtain similar antibacterial activity of $12.5 \mathrm{mg}$ of spherical NPs were necessary 50-100 mg of nanorods. The higher reactivity of the NPs probably leads to a faster release of metallic ions leading to an enhancement of the antibacterial activity for this type of nanostructure.

Finally the effect of the cellulose matrix should also be noted. For this analysis $100 \mathrm{mg}$ of the VC/Cu NPs nanocomposite is used and $50 \mathrm{mg}$ of $\mathrm{BC} / \mathrm{Cu}$ NPs1 so the total amount of inorganic filler is almost the same. For S. aureus the $\mathrm{VC} / \mathrm{Cu}$ NPs nanocomposite presents a similar activity to the $\mathrm{BC} / \mathrm{Cu}$ NPs1 composite. However, comparing the same nanocomposites for the antibacterial action against $K$. pneumoniae, the nanocomposite prepared with VC fibers shows a superior effect. This is an unexpected observation because the $\mathrm{Cu}$ NPs on the VC fibres are not individualized but forming a film, as already reported [12], due to the fast oxidation under normal ambient conditions. Probably this is explained by the preferential deposition of copper on the VC fibers' surfaces which contrasts to the $\mathrm{BC}$ matrix in which the NPs also rely on the $\mathrm{BC}$ structure due to its three-dimensional internal organization, thus acting as a protective cage for the Cu NPs. In this case, the release of $\mathrm{Cu}$ ions is limited as compared to the more open structure of the CV nanocomposite. Similar observations have been reported for materials based on cellulose and Ag NPs, in which for VC/Ag nanocomposites the release of $\mathrm{Ag}^{+}$was superior compared to the $\mathrm{BC}$ analogues [16].

\section{Conclusions}

A series of cellulose/copper nanocomposites have been prepared by varying the type of cellulose used as the matrix (vegetable or bacterial) and also the morphology of copper nanostructures (nanoparticles or nanowires) used as fillers. These composites were investigated for the first time for their antibacterial activity. Antibacterial activity has been observed for the nanocomposite samples against both Gram-positive (S. aureus) and Gram-negative (K. pneumoniae) bacteria. Enhancement of the antibacterial activity with increasing copper content was observed. Among the morphological distinct copper nanostructures used, the nanowires have shown less antibacterial effect that was ascribed to the less reactive surface towards oxidation. Another parameter that influences the antibacterial efficiency of the nanocomposite was the structure of the cellulose fibers. The results suggest that the use of copper together with vegetable cellulose fibers results in better antibacterial materials against both species of tested bacteria. These results confirm the potential of bionanocomposites containing copper nanostructures as new antimicrobial materials. Furthermore this study has shown that formulating composites in which both the matrix and the morphological characteristics of the $\mathrm{Cu}$ fillers are varied can improve the antibacterial action of such materials. These parameters seem to influence the antimicrobial mechanism present that although consistent with a cationic release process still needs further evidence.

\section{Acknowledgments}

Ricardo Pinto thanks the Portuguese Foundation for Science and Technology (FCT) for Grant no. SFRH/BPD/89982/ 2012. The authors also acknowledge FCT (PEst-C/CTM/ LA0011/2011), Fundo Social Europeu (FSE), and Programa Operacional Potencial Humano (POPH) for funding. Microscopy analysis was supported by Rede Nacional de Microscopia Eletrónica (RNME-Pole UA FCT) Project REDE/1509/RME/2005.

\section{References}

[1] J. R. Morones, J. L. Elechiguerra, A. Camacho et al., "The bactericidal effect of silver nanoparticles," Nanotechnology, vol. 16, no. 10, pp. 2346-2353, 2005.

[2] R. J. B. Pinto, M. C. Neves, C. Pascoal Neto, and T. Trindade, "Composites of cellulose and metal nanoparticles," in Nanocomposites-New Trends and Developments, F. Ebrahimi, Ed., pp. 7396, InTech, Rijeka, Croatia, 2012. 
[3] J. P. Ruparelia, A. K. Chatterjee, S. P. Duttagupta, and S. Mukherji, "Strain specificity in antimicrobial activity of silver and copper nanoparticles," Acta Biomaterialia, vol. 4, no. 3, pp. 707-716, 2008.

[4] A. Llorens, E. Lloret, P. A. Picouet, R. Trbojevich, and A. Fernandez, "Metallic-based micro and nanocomposites in food contact materials and active food packaging," Trends in Food Science and Technology, vol. 24, no. 1, pp. 19-29, 2012.

[5] M. J. Hajipour, K. M. Fromm, A. A. Ashkarran et al., "Antibacterial properties of nanoparticles," Trends in Biotechnology, vol. 30, no. 10, pp. 499-511, 2012.

[6] P. V. AshaRani, G. L. K. Mun, M. P. Hande, and S. Valiyaveettil, "Cytotoxicity and genotoxicity of silver nanoparticles in human cells," ACS Nano, vol. 3, no. 2, pp. 279-290, 2009.

[7] M. V. D. Z. Park, A. M. Neigh, J. P. Vermeulen et al., "The effect of particle size on the cytotoxicity, inflammation, developmental toxicity and genotoxicity of silver nanoparticles," Biomaterials, vol. 32, no. 36, pp. 9810-9817, 2011.

[8] N. C. Cady, J. L. Behnke, and A. D. Strickland, "Copper-based nanostructured coatings on natural cellulose: nanocomposites exhibiting rapid and efficient inhibition of a multi-drug resistant wound pathogen, A. baumannii, and mammalian cell biocompatibility in vitro," Advanced Functional Materials, vol. 21, no. 13, pp. 2506-2514, 2011.

[9] J. R. Turnlund, "Human whole-body copper metabolism," American Journal of Clinical Nutrition, vol. 67, supplement 5, pp. 960S-964S, 1998.

[10] K.-Y. Yoon, J. H. Byeon, J.-H. Park, and J. Hwang, "Susceptibility constants of Escherichia coli and Bacillus subtilis to silver and copper nanoparticles," Science of the Total Environment, vol. 373, no. 2-3, pp. 572-575, 2007.

[11] K. C. Anyaogu, A. V. Fedorov, and D. C. Neckers, "Synthesis, characterization, and antifouling potential of functionalized copper nanoparticles," Langmuir, vol. 24, no. 8, pp. 4340-4346, 2008.

[12] R. J. B. Pinto, M. C. Neves, C. Pascoal Neto, and T. Trindade, "Growth and chemical stability of copper nanostructures on cellulosic fibers," European Journal of Inorganic Chemistry, vol. 2012, no. 31, pp. 5043-5049, 2012.

[13] M. Valodkar, P. S. Rathore, R. N. Jadeja, M. Thounaojam, R. V. Devkar, and S. Thakore, "Cytotoxicity evaluation and antimicrobial studies of starch capped water soluble copper nanoparticles," Journal of Hazardous Materials, vol. 201-202, pp. 244-249, 2012.

[14] L. F. Qi, Z. R. Xu, X. Jiang, Y. Li, and M. Wang, "Cytotoxic activities of chitosan nanoparticles and copper-loaded nanoparticles," Bioorganic and Medicinal Chemistry Letters, vol. 15, no. 5, pp. 1397-1399, 2005.

[15] S. V. Manorama, P. Basak, and S. Singh, "Anti-microbial polymer nanocomposites," in Nanocomposite Particles for Bio-Applications, T. Trindade and A. L. Daniel-da-Silva, Eds., pp. 249264, Pan Stanford, Singapora, 2011.

[16] R. J. B. Pinto, P. A. A. P. Marques, C. P. Neto, T. Trindade, S. Daina, and P. Sadocco, "Antibacterial activity of nanocomposites of silver and bacterial or vegetable cellulosic fibers," Acta Biomaterialia, vol. 5, no. 6, pp. 2279-2289, 2009.

[17] R. J. B. Pinto, S. C. M. Fernandes, C. S. R. Freire et al., "Antibacterial activity of optically transparent nanocomposite films based on chitosan or its derivatives and silver nanoparticles," Carbohydrate Research, vol. 348, pp. 77-83, 2012.

[18] B. H. Loo, Y. G. Lee, E. J. Liang, and W. Kiefer, "Surfaceenhanced Raman scattering from ferrocyanide and ferricyanide ions adsorbed on silver and copper colloids," Chemical Physics Letters, vol. 297, no. 1-2, pp. 83-89, 1998.

[19] Y. Chang, M. L. Lye, and H. C. Zeng, "Large-scale synthesis of high-quality ultralong copper nanowires," Langmuir, vol. 21, no. 9, pp. 3746-3748, 2005.

[20] D. Mott, J. Galkowski, L. Wang, J. Luo, and C. Zhong, "Synthesis of size-controlled and shaped copper nanoparticles," Langmuir, vol. 23, no. 10, pp. 5740-5745, 2007.

[21] S. Jadhav, S. Gaikwad, M. Nimse, and A. Rajbhoj, "Copper oxide nanoparticles: synthesis, characterization and their antibacterial activity," Journal of Cluster Science, vol. 22, no. 2, pp. 121-129, 2011.

[22] I. Sondi and B. Salopek-Sondi, "Silver nanoparticles as antimicrobial agent: a case study on E. coli as a model for Gramnegative bacteria," Journal of Colloid and Interface Science, vol. 275, no. 1, pp. 177-182, 2004.

[23] N. A. Amro, L. P. Kotra, K. Wadu-Mesthrige, A. Bulychev, S. Mobashery, and G. Liu, "High-resolution atomic force microscopy studies of the Escherichia coli outer membrane: structural basis for permeability," Langmuir, vol. 16, no. 6, pp. 2789-2796, 2000.

[24] M. A. Vargas-Reus, K. Memarzadeh, J. Huang, G. G. Ren, and R. P. Allaker, "Antimicrobial activity of nanoparticulate metal oxides against peri-implantitis pathogens," International Journal of Antimicrobial Agents, vol. 40, no. 2, pp. 135-139, 2012.

[25] S. Pal, Y. K. Tak, and J. M. Song, "Does the antibacterial activity of silver nanoparticles depend on the shape of the nanoparticle? A study of the gram-negative bacterium Escherichia coli," Applied and Environmental Microbiology, vol. 73, no. 6, pp. 17121720, 2007. 

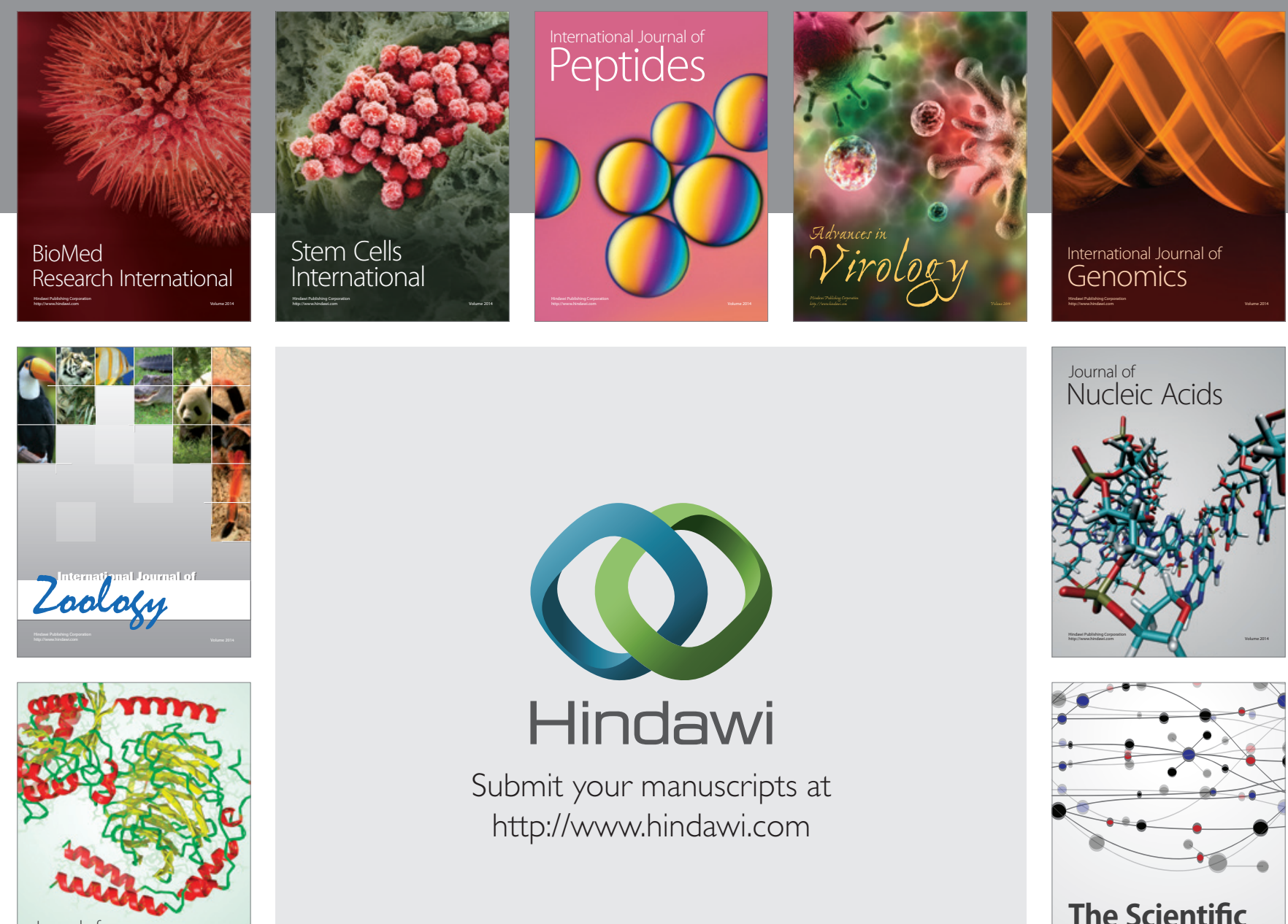

Submit your manuscripts at

http://www.hindawi.com

Journal of
Signal Transduction
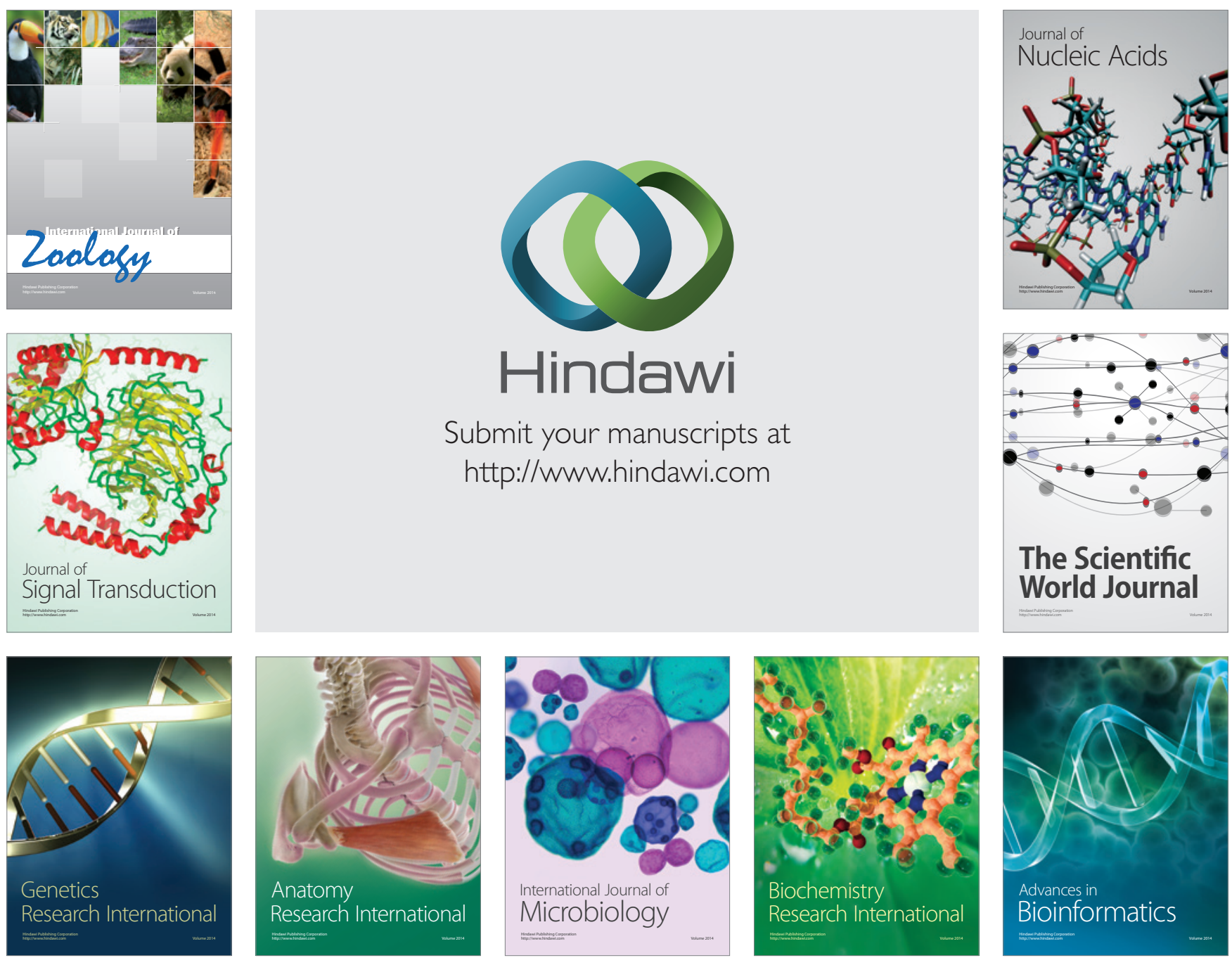

The Scientific World Journal
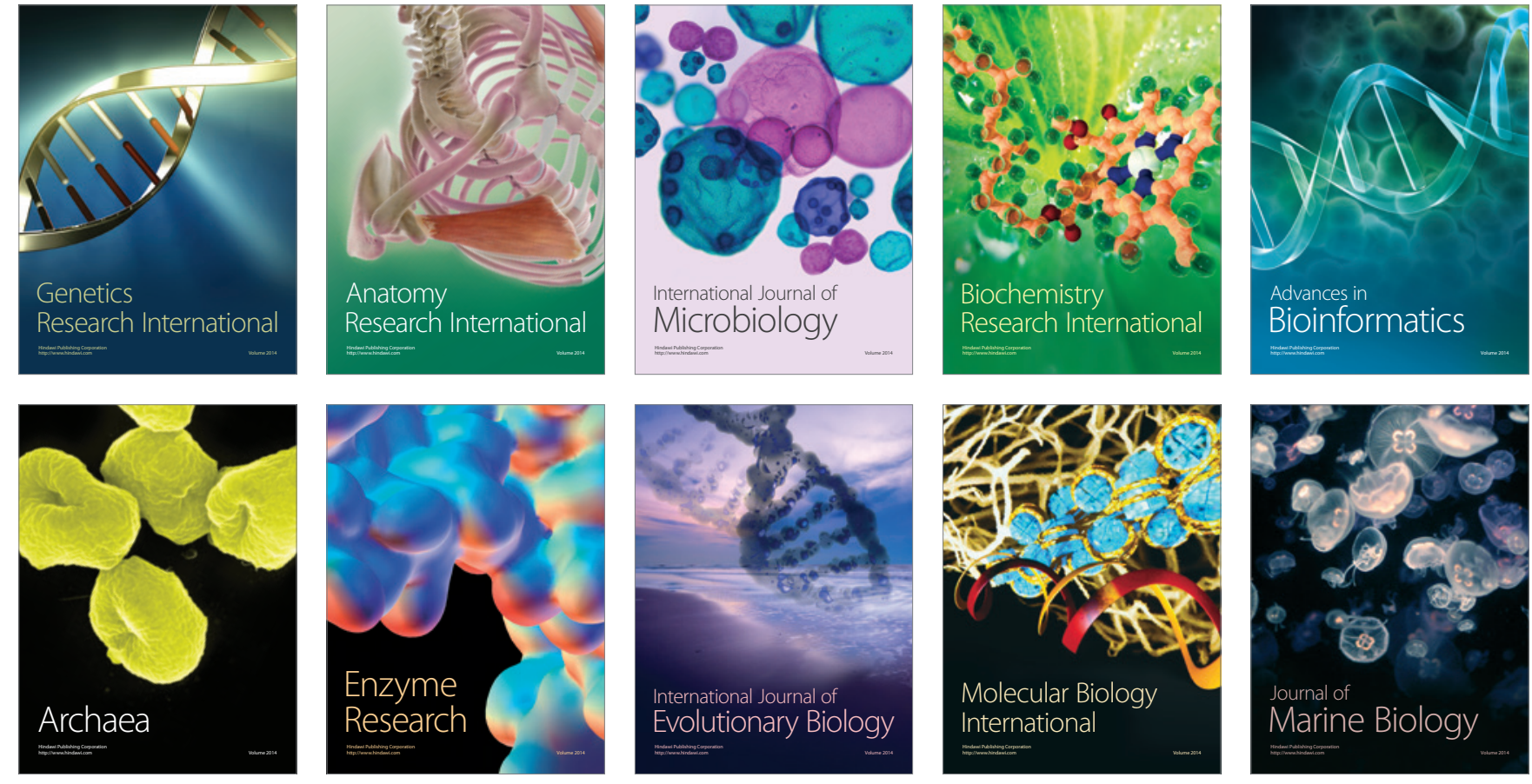